ISSN No. 0974-035X

An Indexed, Refereed \& Peer Reviewed Journal of Higher Education Towards Excellence

UGC-HUMAN RESOURCE DEVELOPMENT CENTRE,

GUJARAT UNIVERSITY, AHMEDABAD, INDIA

\title{
A STUDY ON IMPACT OF SOCIAL NETWORKING SITES ON COLLEGE STUDENTS' CONSUMPTION PATTERNS
}

\section{Dr. Virendra N. Chavda, \\ \&}

Prof. Prashant R Pandya,

\begin{abstract}
:
Social media is a platform for people to discuss their ideas, opinions and issues on various topics. People share or exchange information's, ideas, images and videos even they also communicate with each other through a particular network. Today social networking sites like Facebook, Twitter, LinkedIn, etc., are used by the companies to promote their products. This paper is an attempt to study the effect of social media, particularly Facebook and Twitter on the purchasing habits of future of our country i.e. college students. The study focuses on correlations between various recommendations made by companies on social media and consumption patterns. The study also focuses on role of gender and social media usage frequency on consumption pattern. For the present study, a representative sample of Gujarat Technological University students were taken and analyzed.
\end{abstract}

Key Words: Social networking, Social media, Facebook, Twitter, Consumption pattern

\subsection{Introduction:}

Social Networking has changed the way the youth-lives, socializes and shares. Social media is most recent form of media and having many features and characteristics. It have 
many facilities on same channel like as communicating ,texting, images sharing, audio and video sharing, fast publishing, linking with all over world, direct connecting. Thus Social media allows the interaction among people in which they create share or exchange information and ideas in virtual communities and networks. It has occupied an important place in our lives which is obvious from our gestures of enquiring social networking ids like Facebook id, Twitter handle, etc and also mentioning some on our visiting cards as well. They introduce substantial and pervasive changes to communication between organizations, communities, and individuals. Social networking sites are not only popular for providing a platform for chatting, sharing scraps, videos, pictures, discussing social issues etc., but now companies have taken this as a marketing tool. Companies use these sites as an online location to discuss about product information, news, description and even price.

The evaporation of boundaries between companies and customers, staying connected at minimal extra cost, sharing the products information and spreading it and hence not being on a social networking site is considered queer. Companies use these phenomena and try to connect with their future customers directly with various offerings on social networking sites.

So far several studies had focused on impact of electronic word of mouth communication on consumer behaviour. $\mathrm{Hu}$, Liu \& Zhang (2008) in their study found positive relationship between products with good online reviews and the sales of those products. The more a reviewer was exposed to the product and the more credibility the reviewer had the more influential the individual's feedback became. This word-of-mouth communication had an impact on potential buyers' decisions.

Other research performed by Hyllegard, Ogle, Tan and Reitz (2011) found that many social media websites are being utilized by companies to communicate with customers. Customers are able to express their opinions about a company or brand. LaDuque (2010) 


\section{Chavda \& Prof. Prashant Pandya / Page 1-14}

discovered that companies use social media sites to communicate directly with the customer, as companies are able to increase brand loyalty, create sales leads, and increase publicity through this medium. Furthermore, social media sites are being used for marketing research by both companies and customers (Casteleyn, Mottart, and Rutten, 2009); in addition, customers obtain investigate companies and brands on social media websites.

The present study focuses on to identify the impact of social media, particularly Facebook, on students' consumption patterns.

\subsection{Literature review:}

Social media is means of connections among people in which they create, share, and exchange information and ideas in virtual communities and networks. Alison Doyle an American Psychologist: She define Social media as, it is various online technology tools that enable people to communicate easily and people use social media to share information, text, audio, video, images, podcasts, and other multimedia communication.

Whereas Anthony J. Bradley (2009) he defines Social media is an inevitable for the vast majority of organizations worldwide. He says this predictability is not assurance of success. He says many organizations fail in social-media efforts because they do not deliver their products on the six core principles that set social media apart and bring about its unique value. And these Six Core Principles of are social media collaboration. Social media network site define social media as: it is an online location where people can interact with others about information, entertainment, news and which will be on their own choice and creation.

BBC news research (2013) their research discuss that sixty seven percent Facebook users very common and well known social media portal comprised of the youth and students so this compliment the fact the youth and student have more focus and relation such 
asocial media the negative use of social media occur when students involves themselves in unethical activities on social media portal, sharing of useless information, and posting such as images that are injurious national dignity and foreign relationship of country.

Many studies have supported the idea that a positive correlation exists between online product reviews and sales (Hu, Liu, \& Zhang, 2008). In 2008, Hu, Liu, and Zhang tested the idea that products with favorable reviews sell better than products with unfavorable reviews. In addition, $\mathrm{Hu}$ et al. sought to determine whether the quality of the reviewer (reviewer appears more reliable) would influence the effectiveness of the review.

By analyzing reviews found on Amazon.com's Web Service, Hu et al. (2008) discovered statistically significant differences in sales between products that had favorable and unfavorable online reviews. Finally, the researchers found that consumers also consider reviewer quality and reviewer exposure (the frequency the name of a review is present in the community) when evaluating an online review (Hu et al., 2008). These findings are important because they show electronic word-of-mouth communications do influence consumers, though the influence may be moderated by other factors (Hu et al., 2008). Managers who are seeking to improve electronic word of mouth communications would be better served by targeting the influential reviewers, as their reviews will be given greater consideration ( $\mathrm{Hu}$ et al., 2008). In addition, Hyllegard et al. (2011) found that students "fanned" companies and brands to become market mavens who could receive and disseminate information about brands. This motivation discovered by Hyllegard et al. (2004) is consistent with the "concern for others" motive and "self-enhancement" motives discovered by Hennig-Thurau et al. (2004), as students could improve their knowledge about a product (self-enhancement), and then share this information with friends (concern for others).

In addition, companies have also begun using social media sites as a way to better communicate with customers. According to Hyllegard, Ogle, Yan, and Reitz (2011), 
"between 66\%-96\% of consumer goods companies have adopted social media, including Facebook" (p. 601). One feature of this site is the ability of users to "fan" particular products or brands so that they receive information about these products. In addition, this feature allows customers to express satisfaction or dissatisfaction toward a company or brand. Facebook reports the average user can express interest in over 900 million objects, and the average user follows 80 such pages (Facebook, 2011).

According to LaDuque (2010), companies can also utilize social media platforms to create personalized experiences, to increase brand loyalty, to generate sales leads, and to increase exposure. For example, companies which provide entertaining videos or valuable incentives may have their offerings shared between social media users through electronic word-of-mouth communication. In addition, social networking sites may also allow companies to communicate directly with customers to improve products or address issues. Facebook allows individuals to "like" pages, meaning they will receive updates regarding the product or brand they have "liked." Even mutual fund firms have begun using this medium to communicate with customers, create interactive scavenger hunts, and organize contests among fans (Glazer, 2011).

\subsection{ResearchObjective:}

- To study whether social media websites affect consumption patterns.

- To study effectiveness of word of mouth recommendations on social media differed between genders.

\subsection{Research Methodology:}

\section{- Research Approach \& Nature of Data:}

For gathering primary data, survey approach was used

\section{- Research Instrument:}


For this research questionnaire was used. The questionnaire was divided in two parts; first part focuses on Facebook while second part focuses on consumption pattern. The questionnaire was designed using Likert Scale.

- Sample unit:College students of Gujarat Technological University.

- Sample Size: Total 250respondents of Ahmedabadarea.

- Sample Procedure: Non probability Convenience Sampling

\subsection{Data Interpretation and Analysis:}

\subsubsection{Demographic characteristics:}

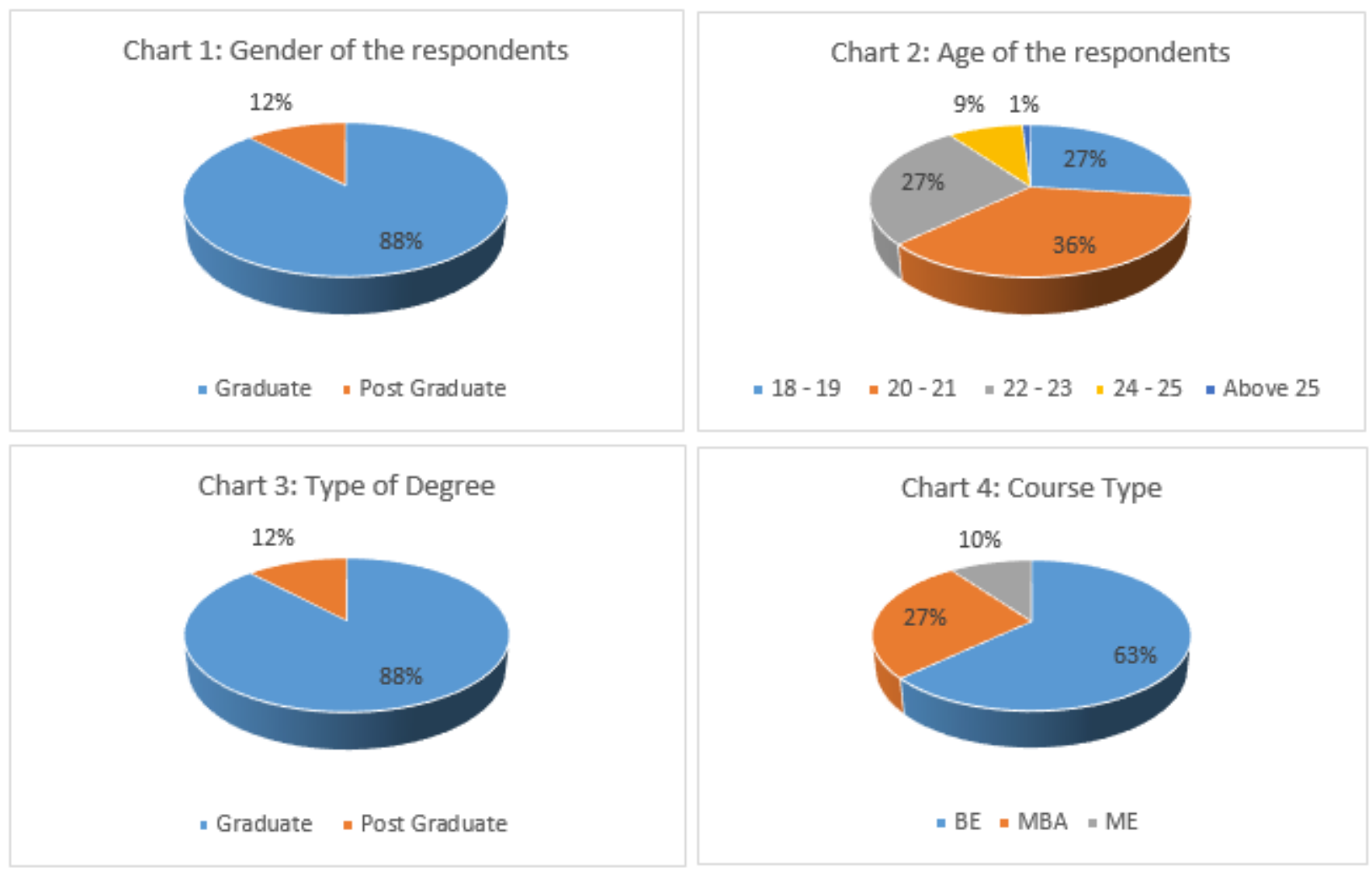

The above charts show the various demographic characteristics of the respondents.

$\mathrm{H}_{1 \mathrm{a}}$ : There is positive effect of Word-of-mouth recommendations on social media websites on consumptionpatterns. 
To analyze this hypothesis, the relationships between below variables were done: number of companies liked, shopping frequency at "Liked stores", frequency of correspondence, frequency of sales, specials or coupons and usage frequency of sales, specials or coupons received from the social media sites.

The results of the Pearson correlations can be found in above Table 1.

From the above correlation analysis, positive correlation found between Facebook friends and Facebook likes, Facebook likes and Facebook shop frequency, Facebook likes and Facebook correspondence, Facebook likes and Facebook sales information, Facebook likes and Facebook sales use, Facebook shop frequency and Facebook sales use and so on.

The results are shown in below table.

\section{Table 1: Correlation Analysis between various variables}


Towards Excellence: An Indexed, Refereed \& Peer Reviewed Journal of Higher Education / Dr. Virendra Chavda \& Prof. Prashant Pandya / Page 1-14

Correlations

\begin{tabular}{|c|c|c|c|c|c|c|c|}
\hline & & Fbfriends & Fblikes & Fbshopfreq & Fbcorrespondence & Fbsalesinfo & FbSalesuse \\
\hline \multirow[t]{3}{*}{ Fbfriends } & Pearson Correlation & 1.000 & $.136^{*}$ & 0.104 & -0.002 & 0.072 & 0.104 \\
\hline & Sig. (2 - tailed) & & 0.027 & 0.072 & 0.909 & 0.225 & 0.071 \\
\hline & $\mathrm{N}$ & 250 & 245 & 242 & 243 & 244 & 242 \\
\hline \multirow[t]{3}{*}{ Fblikes } & Pearson Correlation & $.136 *$ & 1.000 & $.441^{* *}$ & $.380^{* *}$ & $.414^{* *}$ & $.445^{* *}$ \\
\hline & Sig. (2 - tailed) & 0.027 & & 0.000 & 0.000 & 0.000 & 0.000 \\
\hline & $\mathrm{N}$ & 245 & 245 & 247 & 249 & 244 & 247 \\
\hline \multirow[t]{3}{*}{ Fbshopfreq } & Pearson Correlation & 0.104 & $.441 * *$ & 1.000 & $.504 * *$ & $.544 * *$ & $.612^{* *}$ \\
\hline & Sig. (2 - tailed) & 0.072 & 0.000 & & 0.000 & 0.000 & 0.000 \\
\hline & $\mathrm{N}$ & 242 & 247 & 243 & 244 & 249 & 247 \\
\hline \multirow[t]{3}{*}{ Fbcorrespondence } & Pearson Correlation & -0.002 & $.380 * *$ & $.504 * *$ & 1.000 & $.711^{* *}$ & $.555^{* *}$ \\
\hline & Sig. (2 - tailed) & 0.909 & 0.000 & 0.000 & & 0.000 & 0.000 \\
\hline & $\mathrm{N}$ & 243 & 249 & 242 & 243 & 244 & 242 \\
\hline \multirow[t]{3}{*}{ Fbsalesinfo } & Pearson Correlation & 0.072 & $.414 * *$ & $.544 * *$ & $.711^{* *}$ & 1.000 & $.621 * *$ \\
\hline & Sig. (2 - tailed) & 0.225 & 0.000 & 0.000 & 0.000 & & 0.000 \\
\hline & $\mathrm{N}$ & 244 & 244 & 249 & 244 & 244 & 247 \\
\hline \multirow[t]{3}{*}{ FbSalesuse } & Pearson Correlation & 0.104 & $.445 * *$ & $.612 * *$ & $.555^{* *}$ & $.621 * *$ & 1.000 \\
\hline & Sig. (2 - tailed) & 0.071 & 0.000 & 0.000 & 0.000 & 0.000 & \\
\hline & $\mathrm{N}$ & 242 & 247 & 247 & 242 & 247 & 242 \\
\hline
\end{tabular}

**. Correlation is significant at the 0.01 level ( 2 - tailed)

*. Correlation is significant at the 0.05 level ( 2 - tailed)

\section{$\mathbf{H}_{2 \mathrm{a}}$ : There is significant difference between the effectiveness of word of mouth recommendations on social media websites and gender.}

To test this research question and these hypotheses, the mean responses for both genders on questions Facebook friends, Facebook correspondence, were calculated; subsequently, t-tests for independent samples were utilized to determine whether the differences in means were statistically significant at a significance level of .05. Table 2 shows the results for the independent t-tests.

Table 2: Independent sample T test output 
Towards Excellence: An Indexed, Refereed \& Peer Reviewed Journal of Higher Education / Dr. Virendra Chavda \& Prof. Prashant Pandya / Page 1-14

\begin{tabular}{|c|c|c|c|c|c|c|c|c|c|c|}
\hline & & \multirow{2}{*}{\multicolumn{2}{|c|}{$\begin{array}{c}\text { Levene's Test for Equality } \\
\text { of Variances }\end{array}$}} & \multicolumn{5}{|c|}{$t$ - test for Equality of Means } & \multirow{2}{*}{\multicolumn{2}{|c|}{$\begin{array}{l}95 \% \text { Confidence Interval of the } \\
\text { Difference }\end{array}$}} \\
\hline & & & & \multirow[b]{2}{*}{$\mathrm{t}$} & \multirow[b]{2}{*}{$d f$} & \multirow{2}{*}{ Sig $(2$-tailed $)$} & \multirow{2}{*}{ Mean Difference } & \multirow{2}{*}{ Std. Error Difference } & & \\
\hline & & $\mathrm{F}$ & Sig. & & & & & & Lower & Upper \\
\hline \multirow[t]{2}{*}{ Fbcheck } & $\begin{array}{l}\text { Equal Variances } \\
\text { assumed }\end{array}$ & 6.211 & 0.011 & -1.442 & 219 & 0.154 & -0.2 & 0.144 & -0.477 & 0.076 \\
\hline & $\begin{array}{l}\text { Equal Variances } \\
\text { not assumed }\end{array}$ & & & -1.322 & 133.617 & 0.177 & -0.2 & 0.149 & -0.479 & 0.091 \\
\hline \multirow[t]{2}{*}{ Fbfriends } & $\begin{array}{l}\text { Equal Variances } \\
\text { assumed }\end{array}$ & 2.411 & 0.111 & -0.844 & 224 & 0.411 & -0.202 & 0.244 & -0.688 & 0.274 \\
\hline & $\begin{array}{l}\text { Equal Variances } \\
\text { not assumed }\end{array}$ & & & -0.823 & 144.999 & 0.413 & -0.202 & 0.249 & -0.649 & 0.288 \\
\hline \multirow[t]{2}{*}{ Fblikes } & $\begin{array}{l}\text { Equal Variances } \\
\text { assumed }\end{array}$ & 0.357 & 0.544 & -0.666 & 224 & 0.515 & -0.177 & 0.263 & -0.649 & 0.343 \\
\hline & $\begin{array}{l}\text { Equal Variances } \\
\text { not assumed }\end{array}$ & & & -0.654 & 154.599 & 0.504 & -0.177 & 0.262 & -0.699 & 0.341 \\
\hline \multirow[t]{2}{*}{ Fbshopfre } & $\begin{array}{l}\text { Equal Variances } \\
\text { assumed }\end{array}$ & 0.054 & 0.818 & -1.175 & 219 & 0.241 & -0.207 & 0.177 & -0.554 & 0.139 \\
\hline & $\begin{array}{l}\text { Equal Variances } \\
\text { not assumed }\end{array}$ & & & -1.188 & 150.559 & 0.241 & -0.207 & 0.172 & -0.554 & 0.14 \\
\hline \multirow[t]{2}{*}{ Fbcorrespondence } & $\begin{array}{l}\text { Equal Variances } \\
\text { assumed }\end{array}$ & 0.772 & 0.366 & -1.044 & 219 & 0.299 & -0.188 & 0.179 & -0.545 & 0.163 \\
\hline & $\begin{array}{l}\text { Equal Variances } \\
\text { not assumed }\end{array}$ & & & -1.063 & 159.071 & 0.29 & -0.188 & 0.174 & -0.541 & 0.161 \\
\hline \multirow[t]{2}{*}{ Fbsalesinfo } & $\begin{array}{l}\text { Equal Variances } \\
\text { assumed }\end{array}$ & 0.877 & 0.344 & -2.209 & 220 & 0.027 & -0.414 & 0.199 & -0.777 & -0.045 \\
\hline & $\begin{array}{l}\text { Equal Variances } \\
\text { not assumed }\end{array}$ & & & -2.224 & 163.44 & 0.027 & -0.415 & 0.184 & -0.779 & -0.054 \\
\hline \multirow[t]{2}{*}{ Fbsalesuse } & $\begin{array}{l}\text { Equal Variances } \\
\text { assumed }\end{array}$ & 10.117 & 0.001 & -2.215 & 220 & 0.002 & -0.491 & 0.165 & -0.814 & -0.166 \\
\hline & $\begin{array}{l}\text { Equal Variances } \\
\text { not assumed }\end{array}$ & & & -2.129 & \begin{tabular}{|l|}
194.224 \\
\end{tabular} & 0.001 & -0.491 & 0.151 & -0.779 & -0.194 \\
\hline
\end{tabular}

From the above table, differences between males and females were found statistically significant only firstly in receiving information on sales from the companies they have "liked" on Facebook and secondly in using sales and promotions disseminated through Facebook. In both the $\mathrm{p}-$ value was less than the desired significance level of 0.05 , thus the differences between males and females were found to be statistically significant, as females receive more information from these companies regarding sales and discounts and also found that differences between males and females were statistically significant as women take advantage of promotions more often than men. 


\section{Regression Analysis:}

To gain a better understanding of which variables influenced the frequency at which individuals used sales provided to them through Facebook, the following independent variables were analyzed: gender, type of degree, course type, frequency of checking Facebook, number of Facebook friends, number of companies liked on Facebook, frequency of shopping at companies liked on Facebook, frequency of correspondence received from companies on Facebook, frequency of information on promotions received from companies on Facebook and age.

\section{Table 3: Model summary of multiple regression analysis}

\begin{tabular}{ccccc} 
& & \multicolumn{2}{c}{ Model Summary } \\
Model & $\mathrm{R}$ & R Square & Adjusted R Square & $\begin{array}{c}\text { Std. Error of the } \\
\text { Estimate }\end{array}$ \\
1 & .801 & .641 & .621 & .702
\end{tabular}

a. Predictors: (Constant), fbsalesinfo, fbfriends, typeofdegree, coursetype, gender, fbcheck, fblikes, fbshopfreq, fbcorrespondence, age

As shown in above Table, the $\mathrm{R}$ Square value was .641 , meaning that $64.1 \%$ of the variation in sales usage can be explained by the variables analyzed in this analysis. The Adjusted R-Square, which accounts for the large number of variables in the analysis, was .621 .

Table 4: ANOVA output

ANOVA $^{\mathrm{b}}$

Model Sum of Squares df 1 Regression $144.702 \quad 18$

Mean Square $\quad F$ 12.423

Sig. $18.504 .000^{\mathrm{a}}$ 


$\begin{array}{llll}\text { Residual } & 108.009 & 181 & 0.621 \\ \text { Total } & 252.501 & 190 & \end{array}$

a. Predictors: (Constant), fbsalesinfo, fbfriends, typeofdegree, coursetype, gender, fbcheck, fblikes, fbshopfreq, fbcorrespondence, age b. Dependent Variable: fbsalesuse

$F(18,181)=18.504, p<.000$. Because the calculated significance level (.000) was less than the desired level of significance (.05). The results found in Table 4 indicate which coefficients were significant.

\section{Table 4: Significance Tests for Coefficients}

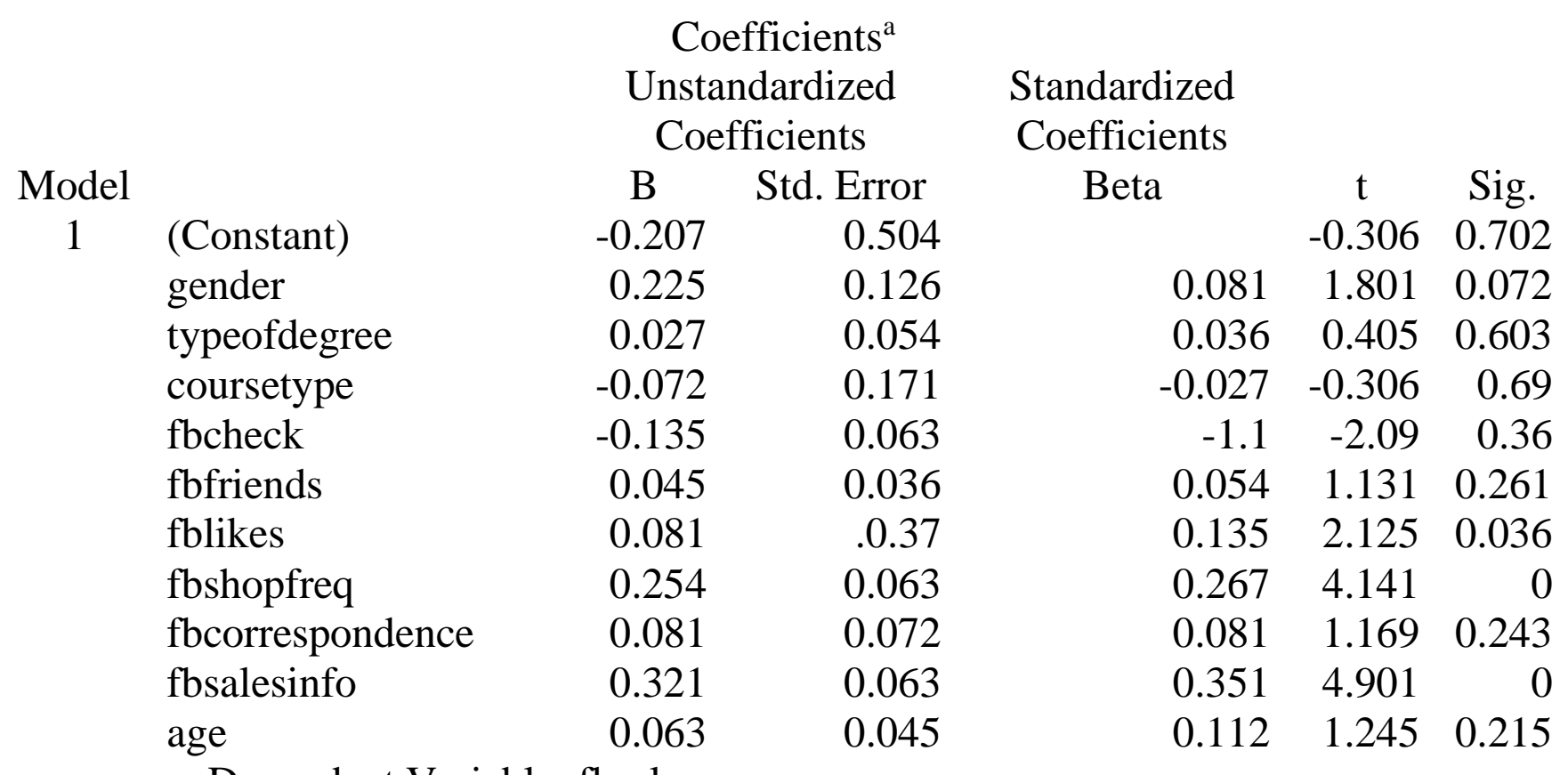

a. Dependent Variable: fbsalesuse

From the above table, the coefficients of frequency of checking Facebook $(p<.036)$, number of companies liked on Facebook $(p<.036)$, shopping frequency at companies liked on Facebook $(p<.000)$, and frequency at which information on sales is received from companies on Facebook $(p<.000)$ were all deemed to be significant. Thus, as individuals "like" more companies on Facebook, shop more frequently at these 
companies, and receive more sales information, they are more likely to take advantage of these promotional offers. Interestingly, this analysis also seems to indicate that as individuals check their Facebook accounts more often, they are less likely to take advantage of the sales and promotional offers they receive through this medium.

\subsection{Major Findings:}

- Students who have more friends on social networking sites and likes or search information about product or service are more likely to like this type of promoting sites.

- Result shows that there is direct relationship between liking a company on Facebook and later on purchase or shopping from the same company.

- The study also found that individuals who follow or friend a larger number of companies are more likely to receive correspondence from these companies.

- Results show that majority of the companies now a days use various social networking sites to communicate with customers.

- Respondents who connected with larger numbers of companies on these sites were likely to receive more sales information than individuals who did not follow a larger number of companies.

- Individuals who shopped more often at companies they had friended on Facebook were more likely to receive information from these companies. These results indicate that individuals are seeing out these companies online and are connecting with them to receive information and individuals are receiving information from companies on social media sites and this information is motivating them to shop more at these stores.

\subsection{Conclusion:}


Many businesses are using social networking sites to reach the customers and promote their products. From the results it is cleared that students receive all types of promotional activities from companies through social media sites. Majority of the students use these information. This arrangement is beneficial to all parties. Businesses that use social media could use either Facebook or any other sites. With comparison of male and female students no differences were discovered in terms of social media use and promotional preferences, so companies can use any social media networking sites for promotion of their business. As results show majority of the females like and search products from online, due to that females receive more news and correspondence on Facebook; companies should emphasize this and try to focus their promotional activity towards female. Overall, college students who use social media more frequently receive more correspondence from companies, and these students then use the promotions. Therefore, businesses should use Facebook or any other social networking site to obtain the patronage of students.

\subsection{Scope for future research:}

- Further study could be conducted to determine the effects of social networking sites on the consumption pattern of different age groups.

- A study also could be conducted to determine the effectiveness of advertising campaigns of companies done with the help of social networking sites. 


\subsection{References:}

- Casteleyn, J., Mottart, A., \&Rutten, K. (2009). How to use Facebook in your market research. International Journal of Market Research, 51(4), 439-447.

- Facebook. (2011). Facebook.com Statistics. Retrieved from http://www.facebook.com/press/info.php?statistics

- Glazer, E. (2017, February 9). Fund firms cautiously tweet their way into a new world. The Wall Street Journal. Retrieved January 18, 2017.

- Hu, N., Liu, L., \& Zhang, J. J. (2008, March 11). Do online reviews affect product sales? The role of reviewer characteristics and temporal effects. Information Technologyand Management, 9(3), 201-214.

- Hennig-Thurau, T., Gwinner, K. P., Walsh, G., \&Gremler, D. D. (2004). Electronic word-of-mouth via consumer-opinion platforms: What motivates consumers to articulate themselves on the internet? Journal of Interactive Marketing, 18(1), 38- 52. Retrieved January 18, 2017.

- Hyllegard, K. H., Ogle, J. P., Yan, R., \& Reitz, A. R. (2011, September). An exploratory study of college students' fanning behavior on Facebook. College StudentJournal, 45(3), 601-616. Retrieved January 18, 2017.

- LaDuque, J. (2010, July). Get more leads, engage customers with social media. In IFAInternational Franchise Association. Retrieved January 18, 2017.

Dr. Virendra N. Chavda, Assistant Professor,

Gandhinagar Institute of Technology, \& E mail: chavdavirendra@ @mail.com, (M): 9428411153
Prof. Prashant R Pandya

Assistant Professor,

\& Gandhinagar Institute of Technology

Email: prpandya07@gmail.com

(M): 9904405943 